\title{
InGaP/GaAsSb/GaAs DHBTs with Low Turn-on Voltage and High Current Gain
}

\author{
B. P. Yan, C. C. Hsu ${ }^{\dagger}$, X. Q. Wang, Y. K. Bai and E. S. Yang \\ Department of Electrical and Electronic Engineering \\ The University of Hong Kong, Pokfulam Road, Hong Kong \\ fax: (852) 25406215, e-mail: bpyan@eee.hku.hk \\ tDepartment of Electronic Engineering \\ The Chinese University of Hong Kong \\ Hong Kong
}

\begin{abstract}
An InGaP/GaAsSb/GaAs double heterojunction bipolar transistor (DHBT) is presented. It features the use of a fully strained pseudomorphic GaAsSb ( $\mathrm{Sb}$ composition: 10.4\%) as the base layer and an InGaP layer as the emitter, which both eliminates the misfit dislocations and increases the valence band discontinuity at the InGaP/GaAsSb interface. A current gain of 200 has been obtained from the InGaP/GaAsSb/GaAs DHBT, which is the highest value obtained from GaAsSb base GaAs-based HBTs. The turn-on voltage of the device is typically $0.914 \mathrm{~V}$ for the $10.4 \%$ Sb composition, which is $0.176 \mathrm{~V}$ lower than that of traditional $\mathrm{InGaP} / \mathrm{GaAs} \mathrm{HBT}$. The results show that $\mathrm{GaAsSb}$ is a suitable base material for reducing the turn-on voltage of GaAs HBTs.
\end{abstract}

\section{Introduction}

One of the major trends for future highperformance mobile handsets is to realize low-power operation so as to reduce the power dissipation and extend the talk-time before recharging of the battery. In order to meet the requirements of low-power operation, several different HBT material systems have been investigated. One of the attractive material systems is InGaAsN base HBT [1-3]. By incorporating a proper amount of nitrogen and indium into GaAs, GaInAsN lattice-matched to GaAs can be obtained with a significant energy band-gap reduction. However, because of the large conduction band discontinuity between InGaAsN base and GaAs collector, a collector current blocking effect would occur, giving rise to a drastic degradation of current gain at a high collector current density. Although by the insertion of graded layers between the base and collector junction, the current blocking effect can be suppressed, this complicates the transistor design and fabrication.

Another effort is to use GaAsSb as the narrow band gap material for the base layer of GaAs HBTs. In comparison with a lattice-matched $\mathrm{GaAs}$ base, the smaller band gap of GaAsSb can reduce the turn-on voltage, thus the power dissipation in circuits. Moreover, the band lineup at the $\mathrm{GaAsSb} / \mathrm{GaAs}$ interface is staggered ("type II") lineup [4], which would eliminate any collector current blocking. GaAsbased HBTs with GaAsSb base layers have been already reported [5-8], but only limited information was given. In the previous work, the grown emitterbase junction was either an $\mathrm{AlGaAs} / \mathrm{GaAsSb}$ [5-7] or a $\mathrm{GaAs} / \mathrm{GaAsSb}$ heterojunction [8], and the devices showed poor dc current gain and large recombination current. It was attributed to the large surface recombination at $\mathrm{GaAs}$ surface and depletion region. Recently, our group implemented a novel InGaP/GaAs $s_{0.94} \mathrm{Sb}_{0.06} / \mathrm{GaAs}$ DHBT, which has an improved current gain and a low turn-on voltage [9]. In this work we increase $\mathrm{Sb}$ composition to $10.4 \%$ in pseudomorphic $\mathrm{GaAsSb}$ base to further reduce the turn-on voltage. At the same time, InGaP is still used instead of $\mathrm{GaAs}$ as the emitter to increase the valence band discontinuity at the emitter-base heterojunction. Thus, we have implemented the InGaP/GaAsSb/GaAs DHBT with a lower turn-on voltage and a higher current gain.

\section{Material Growth and Device Fabrication}

InGaP/GaAsSb/GaAs DHBT structure was grown on a semi-insulating (100) $\mathrm{GaAs}$ substrate by MOCVD. TMGa, TMIn, TMSb, TBP, and TBA were used as the organometallic sources. Carbon and silicon were used as $\mathrm{p}$ - and n-type dopants, respectively. The device structure consists of a $500 \mathrm{~nm} \mathrm{n}>3 \times 10^{18} \mathrm{~cm}^{-3}$ 
GaAs sub-collector, a $500 \mathrm{~nm} \mathrm{n}=5 \times 10^{16} \mathrm{~cm}^{-3} \mathrm{GaAs}$ collector, a $30 \mathrm{~nm} \mathrm{p}=8 \times 10^{18} \mathrm{~cm}^{-3} \mathrm{GaAsSb}$ base $(\mathrm{Sb}$ composition: $10.4 \%$ ), a $50 \mathrm{~nm} \mathrm{n}=3 \times 10^{17} \mathrm{~cm}^{-3} \operatorname{InGaP}$ emitter, a $150 \mathrm{~nm} \mathrm{n}=4 \times 10^{18} \mathrm{~cm}^{-3} \mathrm{GaAs}$ layer, a $50 \mathrm{~nm}$ $\mathrm{n}>1 \times 10^{19} \mathrm{~cm}^{-3}$ compositionally graded $\mathrm{In}_{\mathrm{x}} \mathrm{GaAs}_{1-\mathrm{x}} \mathrm{cap}$ layer $(x=0-0.5)$, and a $50 \mathrm{~nm} n>1 \times 10^{19} \mathrm{~cm}^{-3}$ $\mathrm{In}_{0.5} \mathrm{GaAs}_{0.5}$ cap ohmic contact layer. The $\mathrm{Sb}$ composition was confirmed by high-resolution x-ray diffraction measurement. The surface morphology was observed by atomic force microscope (AFM) and no crosshatched patterns associated with misfit dislocations were observed. This suggests that the $\mathrm{GaAsSb}$ base layer is fully strained. The structure was fabricated into devices using optical lithography and chemical wet selective etching for mesa definition.

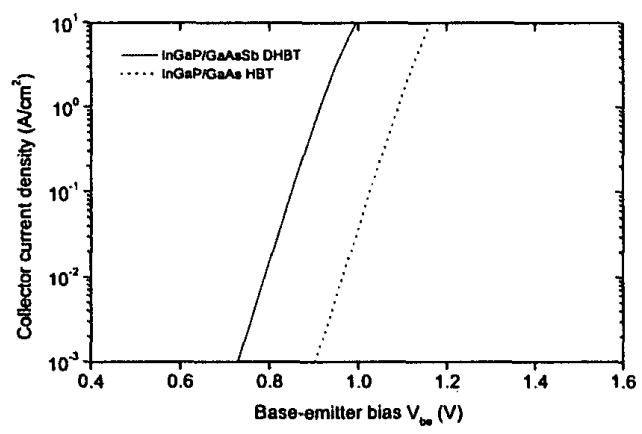

Fig. 1: The dependence of collector current density on emitter-base voltage $\mathrm{V}_{\mathrm{BE}}$ of an InGaP/GaAsSb/GaAs DHBT and an conventional InGaP/GaAs HBT

\section{Device Performance and Discussion}

The dc performances of the devices were measured using a HP4155 semiconductor parameter analyzer. The devices were biased in the common emitter configuration. Figure 1 shows the dependence of the collector current density $J_{c}$ on the emitter-base voltage $V_{\mathrm{BE}}$ of an InGaP/GaAsSb/GaAs DHBT and an InGaP/GaAs HBT with an emitter size of $100 \times 100$ $\mu \mathrm{m}^{2}$. It can be seen that the turn-on voltage of the conventional InGaP/GaAs HBT at $J_{c}=1 \mathrm{~A} / \mathrm{cm}^{2}$ is 1.09 $\mathrm{V}$ and the turn-on voltage of InGaP/GaAsSb/GaAs DHBT is $0.914 \mathrm{~V}$. The turn-on voltage of InGaP/GaAsSb/GaAs DHBT is $0.176 \mathrm{~V}$ lower than that of conventional InGaP/GaAs HBT, indicating that $\mathrm{GaAsSb}$ is a suitable material for reducing the turn-on voltage of $\mathrm{GaAs}$-based HBTs.

Large area InGaP/GaAsSb/GaAs DHBTs $\left(100 \times 100 \mu \mathrm{m}^{2}\right)$ were fabricated on the three layers to assess the epitaxial material quality. Figure 2 shows the common-emitter I-V characteristics of the InGaP/GaAsSb/GaAs DHBT. The device displays uniform current gain under the small current level. The de current gain reaches 100 even at the base current level of $1 \mu \mathrm{A}$. Measured current gain is much higher than previously reported for $\mathrm{GaAs} / \mathrm{GaAsSb}$ DHBTs [5][7]. The improvement of the current gain is attributed to the use of a fully strained pseudomorphic GaAsSb layer, which effectively eliminates the misfit dislocation. Another cause is due to the use of InGaP as the emitter layer, which has a low surface recombination velocity. Measured emitter-collector offset voltage is about $200 \mathrm{mV}$ and the breakdown voltage of emitter-collector $B V_{c e 0}$ is $6-7 \mathrm{~V}$.
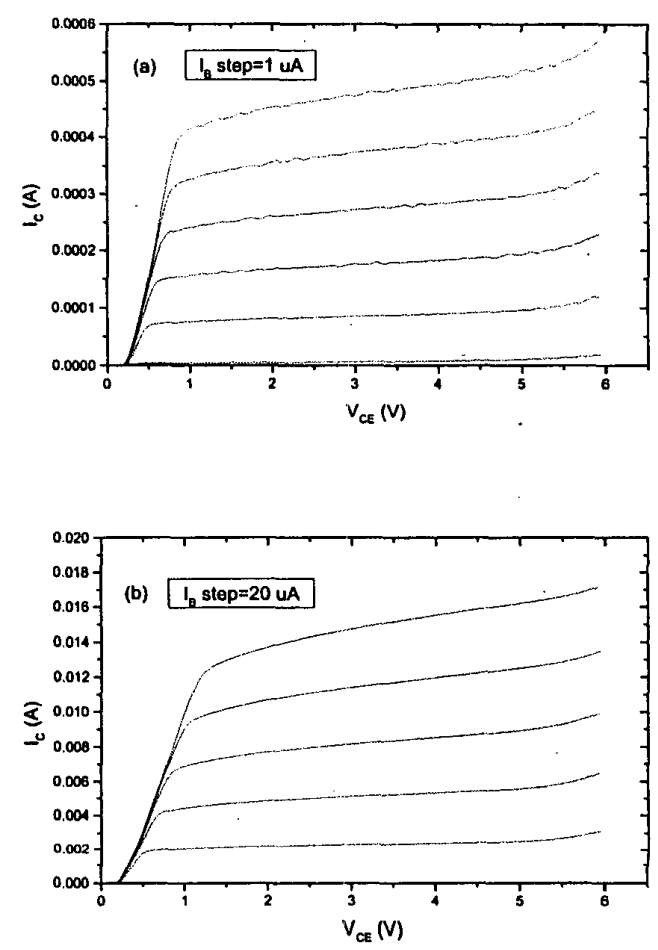

Fig. 2: Common-emitter I-V characteristics for a large area $\left(100 \times 100 \mu \mathrm{m}^{2}\right) \mathrm{InGaP} / \mathrm{GaAsSb} / \mathrm{GaAs}$ DHET under (a) small current (b) large current

Figure 3 shows the dependence of current gain on the collector current. As shown in Fig. 3, when the collector current increases from $0.1 \mathrm{~mA}$ to $50 \mathrm{~mA}$, the incremental current gain $\mathbf{H}_{\mathrm{fe}}$ gain continues to increase. This observation indicates that the baseemitter space charge recombination current is the main base current component [10]. It is understandable, because the base doping is only $8 \times 10^{18} / \mathrm{cm}^{3}$ in this work. A maximum current gain $\mathrm{H}_{\mathrm{fe}}$ 
of 200 has been obtained at a collector current of 50 $\mathrm{mA}$ around.

Figure 4 shows a representative Gummel plot for the large area InGaP/GaAsSb/GaAs DHBT. The ideality factor of the collector current is 1.01 . The base current is significantly divided into two parts. When $\mathrm{Vbe}<0.8 \mathrm{~V}$, the ideality factor of the base current is more than 2.0 and the dominant recombination is the EB junction space charge recombination. When $\mathrm{Vbe}>0.8 \mathrm{~V}$, the ideality factor of the base current is 1.47 , indicating that both the space charge and the base bulk recombination simultaneously make difference. In comparison with $\mathrm{GaAs} / \mathrm{GaAsSb} / \mathrm{GaAs}$ DHBT [8], the base recombination current of $\operatorname{lnGaP} / \mathrm{GaAsSb} / \mathrm{GaAs} \mathrm{DHBT}$ is greatly reduced due to the use of $\mathrm{InGaP}$ as emitter layer. In addition to the improvement of the current gain, the use of InGaP emitter layer is also beneficial to the improvement of device reliability [11]. This work indicates that InGaP/GaAsSb/GaAs DHBT grown by MOCVD in present study is better than $\mathrm{GaAs} / \mathrm{GaAsSb} / \mathrm{GaAs} \mathrm{DHBT}$ and can be a better candidate for the low turn-on voltage device.

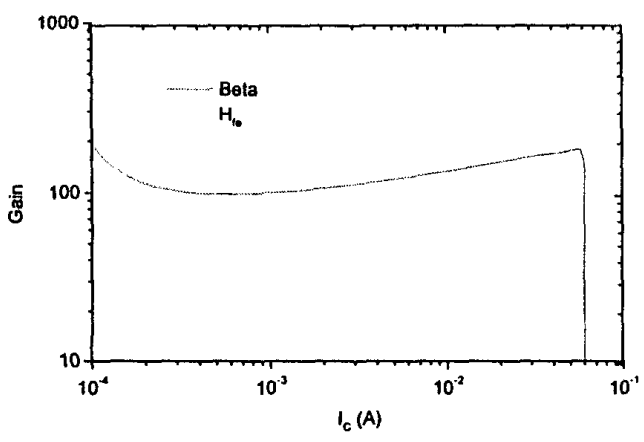

Fig. 3: DC gain $\beta$ and incremental current gain $H_{f e}$ as a function of the collector current Ic.

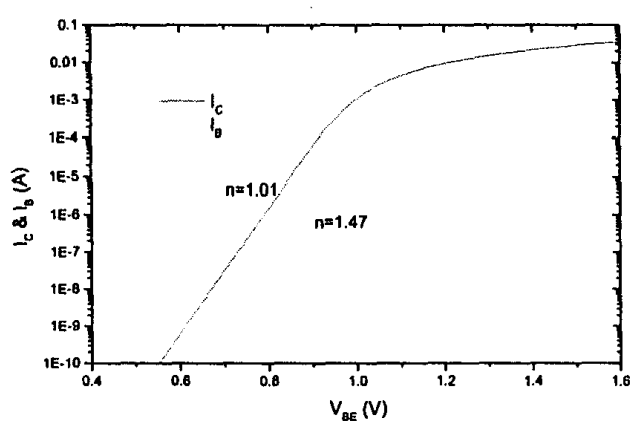

Fig. 4: Representative Gummel plots for $\mathrm{InGaP} /$ $\mathrm{GaAsSb} / \mathrm{GaAs}$ DHBT with an emitter size of $100 \times 100$ $\mu \mathrm{m}^{2}$.
Figure 5 and 6 shows the common-emitter $1-V$ characteristics and Gummel plots for a small area InGaP/GaAsSb/GaAs DHBT, respectively. Devices show a large "knee" voltage and a significant output conductance, which is attributed to the low base doping and the large base ohmic contact resistance.

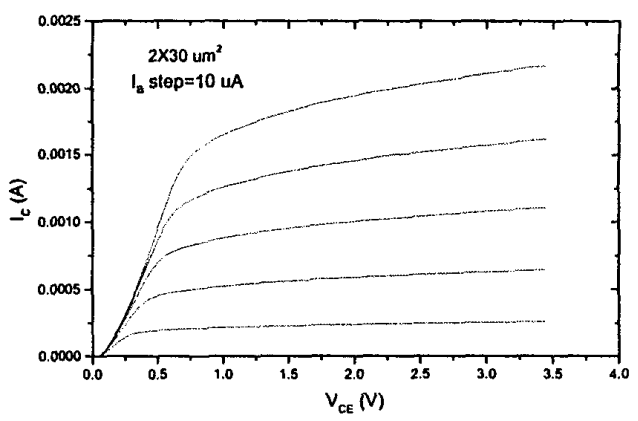

Fig. 5: Common-emitter I-V characteristics of InGaP/GaAsSb/GaAs DHBT with an emitter size of $2 \times 30 \mu \mathrm{m}^{2}$.

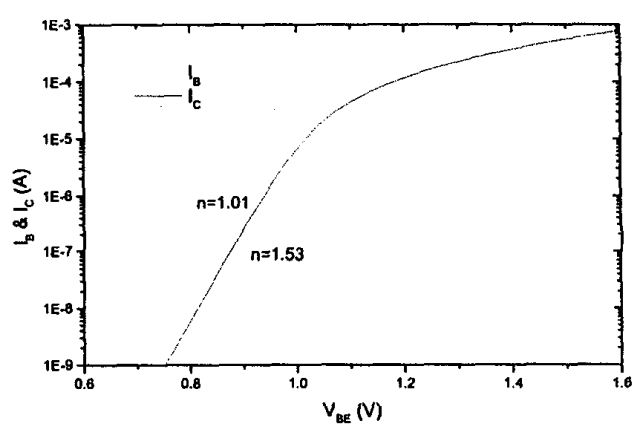

Fig. 6: Representative Gummel plots for InGaP/ $\mathrm{GaAsSb} / \mathrm{GaAs}$ DHBT with an emitter size of $2 \times 30 \mu \mathrm{m}^{2}$.

\section{Conclusion}

In summary, we have demonstrated the low turn on voltage InGaP/GaAsSb/GaAs DHBT, which exhibits excellent DC performances. The device shows a low turn-on voltage, which is $0.17-0.19 \mathrm{~V}$ lower than that of conventional InGaP/GaAs HBTs. These results show that $\mathrm{GaAsSb}$ is a suitable base material for reducing the turn-on voltage of $\mathrm{GaAs}$ HBTs. Our results also reveal that $\mathrm{InGaP} / \mathrm{GaAsSb} / \mathrm{GaAs} \mathrm{DHBT}$ grown by MOCVD is 
better than reported $\mathrm{GaAs} / \mathrm{GaAsSb} / \mathrm{GaAs}$ DHBT Work is under way to optimize material properties to improve further the $\mathrm{DC}$ performance and $\mathrm{RF}$ performances.

\section{Acknowledgement}

The authors would like to thank the support of Research Grants Council of Hong Kong Special Administrative Region, China (Project No. HKU 7057/98E) and CRCG grants (A/C Nos. 37/062/0047 and 10201982). We wish to thank Mr. Ng Fai-Lun in HKUST for his valuable assistance.

\section{References}

[1] N. Y. Li, P. C. Chang, A. G. Baca, X. M. Xie, P. R. Sharps and H. Q. Hou, "DC characteristics of MOVPE-grown Npn InGaP/InGaAsN DHBT," Electron. Lett., vol.36, pp81-83, 2000.

[2] R. E. Welser, P. M. DeLuca, and N. Pan, "Turn-on voltage investigation of $\mathrm{GaAs}$-based bipolar transistors with $\mathrm{Ga}_{1-\mathrm{x}} \operatorname{In}_{\mathrm{x}} \mathrm{As} \mathrm{s}_{1-\mathrm{y}} \mathrm{N}_{\mathrm{y}}$ base layers," IEEE Electron Device Lett., vol.21, pp554-556.

[3] H. Xin, C. W. Tu, P. M. Asbeck, and R. Welty, "Investigation of p-type GaInNAs for heterojunction bipolar transistor base layers," in Proc. Electronics Materials Conf., Santa Barbara, CA, 1999, p.13

[4] R. Teissier, D. Sicault, J. C. Harmand, G. Ungaro, G. Le Roux, and L. Largeau, "Temperature-dependent valence band offset and band-gap energies of pseudomorphic GaAsSb on GaAs," J. Appl. Phys., vol.89, pp5473-5477, 2001.

[5] B. Khamsehpour and K. E. Singer, "GaAsGaAsSb based heterojunction bipolar transistors," Electron. Lett., vol.26, pp 965-967, 1990.

[6] K. Ikossi-Anastasiou, A. Ezis, K. R. Evans, and C. E. Stutz, "Double heterojunction bipolar transistor in $\mathrm{Al}_{\mathrm{x}} \mathrm{Ga}_{1-\mathrm{x}} \mathrm{As} / \mathrm{GaAs}_{1-\mathrm{y}} \mathrm{Sb}_{\mathrm{y}}$ system" Electron. Lett., vol.27, pp142-144, 1991.

[7] K. Ikossi-Anastasiou, "GaAsSb for heterojunction bipolar transistors," IEEE Trans. Electron Devices, vol.40, pp878-884, 1993.

[8] T. Oka, T. Mishima, and M. Kudo, "Low turn-on voltage GsAs heterojunction bipolar transistors with a pseudomorphic GaAsSb base," Appl. Phys. Lett., vol.78, pp483-485, 2001.

[9] B. P. Yan, C. C. Hsu, X. Q. Wang, and E. S. Yang, "A InGaP/GaAs $\mathrm{G}_{0.94} \mathrm{Sb}_{0.06} / \mathrm{GaAs}$ double heterojunction bipolar transistor", IEE Electron. Lett. vol. 38 (6). 2002

[10] W. Liu, "Experimental comparison of base recornbination currents in abrupt and graded AlGaAs/GaAs heterojunction bipolar transistors," Electron. Lett., vol. 27, pp2115-2116,1991

[11] T. Takahashi, S. Sasa, A. Kawano, T. Iwai, T. Fujii, "High reliability InGaP/GaAs HBT fabricated by self-aligned process," In: Proc. IEDM, pp.191-194, 1994 